\title{
Crítica de la educación física y Educación Física Crítica en España. Estado (crítico) de la cuestión
}

Miguel Vicente Pedraz

\begin{abstract}
Resumo: Este trabajo se propone distinguir entre las críticas genéricas a la educación física escolar y las formulaciones de Educación Física Crítica. Tras el análisis de la producción teórica de la última década y el cotejo de sus propuestas con los postulados de la Pedagogía Crítica, se colige que en España no existe representación de esa corriente sino sólo algunas aproximaciones y adscripciones voluntaristas sin un refrendo consistente. Finalmente, se plantean los requisitos fundamentales que la crítica de la educación física debe tener en cuenta para configurar una alternativa teórico-práctica de Educación Física Crítica.
\end{abstract}

Palabras clave: Educación Física Crítica. Escuela. Ideología. Cambio social

\section{INTRODUCCIÓN}

La educación, decía Apple (1999, p. 153) está profundamente comprometida en la política cultural. El currículum, señalaba, nunca es una simple colección de saberes sino que forma parte de una tradición selectiva, de la selección que hace alguien, de la visión que un grupo tiene del saber legítimo, de tal manera que se produce a partir de conflictos, tensiones y compromisos culturales, políticos y económicos que organizan y desorganizan un pueblo.

"Profesor Titular. Facultad de Ciencias de la Actividad Física y del Deporte. Universidad de León. León, España. E-mail: mvicp@unileon.es 
Estas afirmaciones, inspiradas en el pensamiento contrahegemónico de Raymond Williams (2001) y traída a colación en diversas ocasiones por el autor de Ideología y currículo -al menos desde la publicación de esta pieza fundamental de la Pedagogía Crítica, en 1979-, no constituye, en lo principal de la formulación, motivo de controversia en la mayoría de los foros donde el objeto de estudio es o bien las políticas educativas o bien la sociología de la escuela, la educación comparada, incluso, la historia o la filosofía de la educación, etc., disciplinas todas ellas afanadas en la comprensión de los fenómenos y las prácticas educativas y, por qué no decirlo, interesadas también en su transformación. Sin tener que remontarnos a los orígenes de la tradición crítica donde ya aparecía una caracterización de la escuela como aparato al servicio de las clases dominantes y de la cultura hegemónica, autores que van desde el propio Raymond Williams a Basil Bernstein, pasando por Freire, Bourdieu, Popkewitz, Shapiro, McLaren, Giroux, da Silva o, ya en España, Carlos Lerena, Fernández Enguita, Álvarez Uría, Raimundo Cuesta, etc. han puesto de relieve, aunque desde distintas perspectivas, el papel de la escuela y del sistema educativo, en general, en la inequitativa producción-distribución del saber así como de los recursos materiales y simbólicos que contribuyen a la perpetuación de las estructuras de dominación y, subsidiariamente, a legitimar la cultura hegemónica.

Otra cosa muy distinta es que curricularmente se hayan desarrollado, de manera efectiva, estrategias que permitieran atenuar esta espuria condición. Especialmente ahora que los vientos neoliberales nos devuelven las falacias meritocráticas, cargadas con la razón económica, difícilmente las políticas educativas (VICENTE, 2011) pueden romper el bucle reproductivo tan consustancial a la tradición selectiva del sistema escolar.

A este respecto, pocas materias escolares han llevado a cabo su particular análisis introspectivo tal que haya permitido comprender hasta qué punto los contenidos, las metodologías, los recursos, los 
materiales, los objetivos, etc. que les son propios, contribuyen o no a la reproducción de la cultura hegemónica y sus desigualdades para, en su caso, acometer actuaciones paliativas.

Del conjunto de las materias escolares, la educación física constituye un caso de particular interés. A pesar de no ser una materia de alto estatus - según la terminología de Apple, (1986, p. 54) - ha conseguido generar una apreciable cantidad de discurso en comparación con las materias académicas de su mismo rango e, incluso, en comparación con las materias consideradas de alto estatus. Desde luego, la mayor parte de la producción teórico-práctica que se genera en el ámbito de la educación física se circunscribe al ámbito técnico y dentro de este, especialmente, al didáctico: producción de materiales curriculares y estrategias didácticas, análisis de contenidos, desarrollo de metodologías, estudio de variables de programación, etc. donde la orientación teórica, antes que crítica, ha sido generalmente de carácter instrumental, actuacional, en su sentido más inmediato. No obstante, y aunque en menor medida, las preocupaciones teórico-prácticas en el campo de la educación física también han logrado generar un importante discurso epistemológico y humanístico cuyos inicios en España se remontan a mediados de los años sesenta cuando tan solo dos revistas científicas -las Cátedras Universitarias de Temas Deportivo-Cultural y Citius, Altius Fortiusdaban cobertura a todas las iniciativas de investigación o reflexión al respecto.

Desde entonces y hasta ahora -momento en que las revistas de educación física se cuentan en España por decenas-, tanto en el terreno didáctico como en el epistemológico-humanístico, ha predominado un discurso acomodaticio, de corte legitimista (VICENTE 2011), exento en la mayor parte de las ocasiones de consideraciones críticas y, mucho más, exento de análisis políticos e ideológicos profundos a propósito de la materia y sus atributos. Ello no quiere decir que exista una única visión de la educación física. De hecho, especialmente en las dos últimas décadas no han dejado 
de aparecer notables contribuciones donde el currículum de la educación física y sus fundamentos teórico-prácticos han sido sometidos al escrutinio de la crítica bajo diferentes puntos de vista: muchas de ellas, al calor de las frecuentes reformas educativas y otras como resultado de investigaciones de amplio alcance a través de las que muchos profesores-investigadores tratan de dotar a la materia recursos más eficientes y mejores justificaciones. Llama la atención que, de entre todas ellas, muchas son presentadas como propuestas de educación física alternativa; encaminadas al cambio

Pues bien, algunas de estas propuestas de educación física alternativa han sido denominadas por sus propios autores (DEVIS, 1998; FRAILE, 1999; FERNÁNDEZ-BALBOA, 1999, 2004; PASCUAL, 2000, 2002; LÓPEZ et al., 2002a; SICILIA; FERNÁNDEZ-BALBOA, 2005) como formulaciones de Educación Física Crítica o Didáctica de la Educación Física Crítica, lo que, desde nuestro punto de vista, puede resultar equívoco. Siendo que dicha acepción deriva, por analogía, del concepto de Pedagogía Crítica, parece necesario que al menos los principales elementos epistemológicos e ideológicos de la corriente matriz constituyan la base de la construcción teórica que pretende adscribirse a dicha corriente; algo que sólo en muy escaso grado y de manera demasiado difusa, aunque con gran voluntarismo, ocurre en cuantas propuestas reformadoras de la educación física hemos encontrado.

Más allá del uso apropiado o no de los términos y sus significados, el empleo del concepto de Educación Física Crítica para referir propuestas que sólo tangencialmente son alternativas metodológicas, desde nuestro punto de vista puede tener como perversa consecuencia la minoración de la propuestas que pudieran hacerse desde los principios teórico-prácticos de la Pedagogía Crítica e, incluso, la emergencia de la misma como alternativa a los modelos de educación física vigentes. Es notorio, a este respecto, cómo en aquellos entornos culturales y países donde la Pedagogía Crítica ha sido una punta de lanza del debate educativo desde sus inicios como es el caso de Brasil-, las propuestas de Educación Física Crítica han mantenido y mantienen un pulso propositivo y transformador - 
por ejemplo, Marín et al. (2012)- o de resistencia -por ejemplo, Lemos et al. (2012)-, cuyas perspectivas difícilmente pueden hallarse allí donde los modelos educativos han sido fagocitados casi en su totalidad por la racionalidad técnica y por los requerimientos de la sociedad de consumo.

A este respecto, el objetivo del presente artículo es diferenciar entre las críticas (genéricas) a la educación física en tanto que disciplina escolar incluyendo las que se configuran como propuestas de cambio y las (posibles) formulaciones teóricas de la Educación Física Crítica en el contexto español. Tratamos de poner de relieve el estado de la cuestión tomando como referencia las exigencias que la teoría de la educación física debería cumplir para hacerse acreedora de una adscripción con tanta relevancia ideológica y tan grande intención transformadora, no para restar mérito al ingente y valioso trabajo crítico realizado en los últimos años, sino con el objeto de abrir un debate sobre la educación física que tenemos y sobre los caminos que pueden recorrerse -o construirse- para lograr una educación física con mayor pertinencia pedagógica y con mayor significación social.

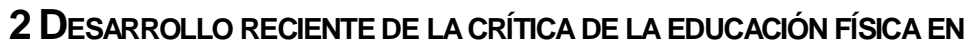 ESPAÑA: ESTADO DE LA CUESTIÓN}

Incluso teniendo en cuenta que la mayor parte de la producción teórico práctica en el ámbito de la educación física mantiene unos planteamientos muy conservadores -a menudo, anclados en una concepción aún de carácter higienista-, la creciente investigación en el campo del currículum ha experimentado una apertura del espectro del debate a niveles difícilmente imaginables hace tan solo treinta años. Además de los trabajos que puntualmente han ido analizando críticamente la posición en la que cada reforma educativa dejaba a la educación física escolar, en este periodo se puede constatar un efectivo y recurrente trabajo crítico en torno a las cuestiones curriculares fundamentales. Asimismo, con una perspectiva de mayor alcance, se puede destacar un buen número de trabajos, 
también críticos, en relación con la desigualdad y la necesaria atención a la diversidad -especialmente prolijo en aspectos relacionados con el género o con alumnos que presentan alguna discapacidad y con alumnos inmersos en situaciones de exclusión-. Son recurrentes los trabajos críticos en relación con el autoconcepto corporal, propuestas didácticas para el estímulo de la cooperación frente a las prácticas de carácter competitivo, así como formulaciones orientadas al fomento de la tolerancia, el respeto y los valores democráticos en general. No debemos olvidarnos de las emergentes propuestas de cambio de racionalidad en la investigación en el campo.

Ahora bien, reconociendo y elogiando la trayectoria de los investigadores que han impulsado el desarrollo de la disciplina a los niveles de discusión en los que hoy se encuentra en España, es preciso, preguntarse si, como algunos autores sugieren (LÓPEZ et al., 2002b; LÓPEZ; MONJAS; PÉREZ, 2003; UREÑA, 2005; SICILIA; FERNÁNDEZ-BALBOA, 2005; MUÑOZ, 2006; GÓMEZ; PRAT, 2009; LÓPEZ; GEA, 2010), dichos trabajos constituyen la expresión de la Educación Física Crítica en España. Habría que preguntarse si es suficiente mostrar discrepancias de carácter metodológico, e incluso epistemológico, para hablar de Educación Física Crítica. Es necesario preguntarse si es suficiente llevar cabo un análisis más menos reflexivo y participativo de la educación física o hacer una crítica del currículum oficial para sostener la adscripción a la Pedagogía Crítica.

Desde nuestro punto de vista y a pesar de la heterogeneidad del concepto de crítica, hablar de Educación Física Crítica exige mantener planteamientos teóricos-prácticos así como principios ideológicos y de política educativa propios de la Teoría Crítica y, particularmente, de la Pedagogía Crítica. Sin dichos planteamientos, la crítica, sin dejar de serlo, y en muchos casos sin perder su capacidad transformadora, no constituye una condición suficiente de adscripción a dicha corriente pedagógica cuya primera característica tal vez sea el carácter diverso, pero dialógico, de sus partícipes. De hecho, estos, en su recorrido de casi medio siglo, han dado lugar a posiciones tan distintas como las que se dan entre las propuestas de educación 
popular en América latina y las propuestas de la pedagogía radical norteamericanas, entre las teorías de la reproducción típicamente europeas y la teoría crítica del currículum australiana, entre otras, todas las cuales, en todo caso, coinciden el profundo compromiso con la política cultural según señalábamos en la cita inicial.

\section{Consideraciones sobre la Teoría Crítica y sobre la Pedagogía Crítica}

Aunque la Pedagogía Crítica se desarrolla a partir de fuentes muy diversas, especialmente heterogéneas en la fase que podríamos denominar de madurez -a partir de la década de los años ochenta-, su impronta no es otra que la Teoría Crítica de la sociedad, algunos de cuyos principios epistemológicos, metodológicos e ideológicos enunciados como cuerpo teórico básico por los integrantes de la Escuela de Frankfurt- deben considerarse irrenunciables.

En primer lugar, es preciso tener en cuenta el propósito básico de encontrar una construcción teórica capaz de explicar las complejas interacciones del capitalismo avanzado desde la no aceptación de un estado histórico en el que lo que "es" no "debería ser" (HORKHEIMER; ADORNO, 2009); es decir, desde el rechazo de la "teoría tradicional" cuya racionalidad nomológica y positivista presenta la realidad de un modo estático y armónico. Una racionalidad, la positivista, que pone bajo sospecha la diferencia, al diferente mediante la aplicación sistemática del concepto determinaciones universales que identifican un número infinito de casos particulares- cuya abstracción idealista de la realidad tiende a anular todo aquello que en el individuo no pueda ser reconocido como un rasgo universal, idéntico en todos los de su especie. El concepto supone, así, la violenta anulación de la diferencia que, aplicada a la sociedad, se configura como una reducción de las relaciones humanas y del hombre mismo a meras "cosas", a meros objetos, independientes de los conflictos, los intereses y los valores de los propios sujetos que las producen sometiéndolos a la unidad, a la regla, y ocultando el carácter ideológico de toda teoría. 
De entre los instrumentos de dominación que sirven a la razón instrumental resulta fundamental la separación de las esferas del ser y del deber ser y, como consecuencia de ello, la deslegitimación y mitologización de toda discusión posible sobre los valores en nombre de una objetividad que se aplica a registrar lo existente, desde el punto de vista de lo existente, limitando el conocimiento a una mera replicación de lo ya dado con vistas a su dominio técnico; con tales planteamientos, el positivismo se priva a sí mismo de la posibilidad de trascender, de superar lo que hay, esperando una suerte de evolución "natural" de lo existente.

Frente a ellos, plantean los frankfurtianos, sólo queda ilustración, crítica y razón; pero no la razón instrumental, que reduce el sujeto al objeto y supedita los medios a los fines lejos de cualquier consideración moral, sino razón crítica cuya dialéctica negativa no está orientada a interpretar el mundo ni tampoco a que todo funcione mejor sino al encuentro del conocimiento con la justicia resistiéndose a la complicidad con los principios de dominación social presentes en la industria cultural y la cultura de masas. Contra dichos principios de dominación, la Teoría Crítica se configura como una alternativa teórica que afirma la relatividad del conocimiento así como el carácter mediado (históricamente) de este a través de la praxis social en su totalidad; es decir, como una mediación mutua y permanente del sujeto y el objeto donde no hay un orden absoluto, prefigurado, ni una verdad dada que descubrir. El conocimiento es más bien la expresión continua de un proceso dialéctico en el que las tensiones entre sujeto y objeto expresan la magnitud de la tarea a realizar; pero una tarea siempre referida a la totalidad y no, como en el pragmatismo, al interés economicista e inmediato.

En este sentido, acercamiento de la razón a la justicia, emancipación de las ataduras del dominio que ejerce la cultura de masas y la mitología del positivismo científico, desentrañamiento de las contradicciones que sostienen las miserias del presente, voluntad de transformación, etc., son algunos de los caracteres de esa dialéctica que, a diferencia de la dialéctica ilustrada, no es positiva. Es, como hemos apuntado, negativa, "porque atenta contra la 
tradición" (ADORNO, 2011); porque niega, por ideológicos, los conceptos universales; porque, frente a las proposiciones asertivas y justificacionistas, se construye mediante interrogaciones permanentes con el objeto de descubrir las contradicciones del discurso; asimismo, porque frente a los positivismos empíricos con cuyos recursos (materiales, intelectuales, etc.) no se ha logrado erradicar la explotación del hombre por el hombre, la negación del "ser" por comparación con el "deber ser" es el único motor posible de la Historia.

La aplicación de estos principios, entre otros que confluyen en la Pedagogía Crítica, supone el reconocimiento del carácter político de toda acción pedagógica en aras de una educación racional, democrática, equitativa y emancipadora. No reconocer dicho carácter es en cierto modo retirar de la escena el debate sobre el papel de la escuela como agente de construcción y distribución inequitativa- del saber, remitiendo a la mitología meritocrática la convicción de que en ella se enseña a todos por igual aquello que todos necesitan aprender.

Consecuentemente al reconocimiento del carácter político de la acción pedagógica, la Pedagogía Crítica toma partido. Más allá de la aplicación técnica de las variables genéricas de aprendizaje, se pregunta por las condiciones materiales, sociales y culturales en las que los sujetos aprenden o no lo hacen. A este respecto, constatando que la escuela no ha servido para resolver los problemas de desigualad en el acceso a la cultura, adquiere el compromiso de transformación desde presupuestos, antes que técnicos -aunque también estos-, ideológicos y políticos.

Es irrenunciable para la Pedagogía Crítica el abordaje de la escuela como un campo de luchas -simbólicas, culturales, sociales y, por qué no decirlo, económicas- que es preciso analizar desde una perspectiva, según hemos planteado, histórica, dialéctica y negativa. Histórica, porque la genealogía permite desnaturalizar lo que ya aparece como sustancial y necesario en la institución escolar y, por lo tanto, incuestionable. Dialéctica, porque, siendo la escuela un campo de luchas en constante cambio, sólo el discernimiento de las 
categorías que intervienen (y se oponen) en cada contienda cultural que se libra dentro de ella, puede desvelar las contradicciones que ha de soportar la institución para preservar su legitimidad meritocrática. Negativa, porque niega, por ideológicamente falaces, la sustantividad y la necesidad de los principios, las estructuras, los recursos, la lógica y los objetivos del currículum; porque niega la naturaleza "natural" -psicobiológica- y la naturaleza técnica pedagógica- de las diferencias individuales que se desprenden del paso por la escuela; asimismo, porque desde la negación de los postulados de la pedagogía tradicional pretende catapultar el cambio hacia una educación racional, crítica y emancipadora.

\section{De la crítica de la educación física a la Educación Física Crítica}

De acuerdo con estos planteamientos, las perspectivas desde la que muchos teóricos han abordado la crítica de la educación física en España, si bien ha supuesto un cambio cualitativo en la consideración de la disciplina, no pueden considerarse como formulaciones de Educación Física Crítica dado que se mantienen dentro la lógica de la racionalidad instrumental y técnica; se limitan a reprobar las carencias o los desajustes del sistema de enseñanza de la educación física con el propósito de mejorar su eficiencia pedagógica pero dentro de los límites tolerables de discusión funcional que todo sistema se fija a sí mismo; es decir, hasta allí donde la crítica no pone en riesgo el statu quo.

Como premisa diferencial básica es preciso señalar que frente la crítica de la educación física, cuyo objetivo específico es transformar la disciplina y sólo genéricamente la sociedad, la Educación Física Crítica solo puede configurarse como tal en tanto que formulación teórico-práctica que trate de impulsar un cambio social concreto a partir de una propuesta educativa sobre el cuerpo que se reconozca a sí misma como acción sociocultural y política cuyos elementos de configuración puedan identificarse como coagentes de la Pedagogía Crítica. La desigualdad social y cultural 
encuentra en el cuerpo un espacio privilegiado en el que inscribe sus marcas las cuales anteceden y suceden el espacio-tiempo de la clase de educación física; pues bien, si los cambios en la disciplina no tratan de trascender ese espacio-tiempo y contribuir con ello a la disolución de dicha desigualdad, sólo serán un aderezo que, incluso, al ofrecer una imagen dinámica de la disciplina, pueden contribuir a perpetuar el universo simbólico y práctico que conforma el estrecho paradigma de la racionalidad instrumental.

Una condición necesaria de esta formulación es, de acuerdo con la Teoría Crítica, la no aceptación del estado de cosas como algo necesario. Para el caso que nos ocupa, el rechazo de la consideración de la educación física como el resultado de un proceso evolutivo y lineal emanado de unas necesidades objetivas y naturales -sustanciales-, de educación del cuerpo que, en esencia, se considera neutro. Frente a ello, la Educación Física Crítica ha de considerar la disciplina como una construcción contingente, resultante de la confrontación (simbólica, ideológica, práctica, etc.), de representaciones diferentes en torno al gobierno de los cuerpos en el que cada contendiente (cultura, clase, fracción de clase, grupo de presión, minorías, etc.) pone a prueba sus propias concepciones y cuyo desenlace es sometido a un proceso subsecuente de legitimación mediante un bucle autorreproductivo de discurso, prácticas, reglamentaciones, demandas sociales, etc.

El constructivismo histórico-crítico, de acuerdo con Elias (1990), subraya la historicidad de la disciplina pedagógica y la propia historicidad del cuerpo cuya presencia (apariencia, gestos, disposiciones, dimensiones, etc.), según han constatado Boltanski (1972) o Bourdieu (1986), es un indicador del lugar que cada cual ocupa en la escala social. Con ambos ingredientes debe analizar la dialéctica de las diferencias en el acceso a la cultura corporal legítima constituyéndose como una alerta sobre el efecto perverso que el trabajo por el acceso a dicha cultura tiene sobre los sujetos pertenecientes a los grupos minoritarios y sobre aquellos sujetos que se hallan en los márgenes de lo legítimo. Puesto que ninguna sociedad es tan compacta y uniforme, ni está tan libre de tensiones, tal que se 
pueda hablar del cuerpo en un sentido unitario, la Educación Física Crítica, en la medida en que trata de responder a los intereses y expectativas de todos y cada uno de los miembros de la comunidad escolar, ha de poner de relieve la violencia simbólica que supone tratar la cultura corporal como un patrimonio común e indiferenciado, como algo homogéneo, con significados unívocos. En este sentido, ha de advertir del carácter arbitrario de la selección de prácticas que la educación física escolar oficial distribuye como neutras, como universalmente formativas y sustentadas en conocimientos "verdaderos".

A este respecto, una cuestión fundamental para la Educación Física Crítica es el análisis de la disciplina en tanto dispositivo ideológico de configuración de la subjetividad. Más allá de la toma en consideración genérica del poder como retícula en cuyo interior se configura el sujeto, McLaren (1997, p. 58) -siguiendo a Foucaultplantea que las escuelas no sólo no son neutras sino que tampoco son ideológicamente inocentes ni se limitan a reproducir las relaciones e intereses sociales dominantes; producen, además, formas de regulación política y moral íntimamente conectadas con las tecnologías del poder las cuales, producen asimetrías en las habilidades de los individuos y grupos para definir y percatarse de sus propias necesidades. Es palmario que la inmersión de cualquier sujeto desposeído de la cultura hegemónica en cualquier espacio disciplinar de la escuela -y no menos en el de la educación físicaacaba siendo capilarizado y capitalizado por los modos dominantes de comprender el sí mismo hasta reconfigurar su subjetividad; sin embargo, tal vez nunca tanto como para producir una asimilación (integración) del sujeto a la cultura hegemónica en igualdad de condiciones ni tan poco como para que la transformación que experimenta el sujeto no llegue a provocar un conflicto de valores en torno al uso de su cuerpo y probablemente de su identidad social. Siendo las escuelas encarnaciones históricas y estructurales de formas ideológicas reproducidas mediante alineaciones discursivas que privilegian a determinados grupos, apunta McLaren (1995, p. 57), dan significado a la realidad a través de formas unitarias que, sin 
embargo, no logran reconocer el proceso heterogéneo, múltiple y a veces contradictorio de conformación de la subjetividad. Y es que, como señala Giroux: "La escuela acalla activamente a los estudiantes a través de ignorar sus historias, de encuadrarlos dentro de clases con expectativas mínimas y de negarse a proporcionarles conocimientos relevantes para ellos" (GIROUX, 1998, p. 81).

Pues bien, desde la perspectiva de la Pedagogía Crítica es preciso que la escuela en general y la educación física en particular irrumpan directamente en este terreno, tal vez en dos momentos. Inicialmente, mediante la recontextualización de los sujetos y sus corporalidades, es decir, mediante la devolución de las señas de identidad que a cada cual le es hurtada como condición de su ingreso en la institución, supuestamente neutra, de tal modo que todas las variables de conducta puedan ser comprendidas desde la identidad diferencial y desde el capital cultural previo que las determinan. Posteriormente, mediante la adecuación del trabajo pedagógico sobre el cuerpo no a los recursos y discursos de aprendizaje gradual, metódico, sistemático y evaluable de la educación física sino a las necesidades tanto materiales como culturales de los sujetos involucrados en ella.

El primer momento exige revertir el proceso por el cual el cuerpo-sujeto es convertido en el cuerpo abstracto -"[...] el sujeto puro, perfectamente sublimado y desprovisto de tradición", en la terminología de Adorno (2011, p. 60) - colocando sobre el tapete pedagógico las relaciones de poder que entran en juego en la construcción de la subjetividad escolar. Exige romper con el cuerpoconcepto, el cuerpo genérico, que el paradigma discursivo de la educación física ha encontrado en el modelo anatómofisiológico cuya incontestabilidad científica otorga a la escuela autoridad impositiva y legitimidad clasificatoria.

El segundo momento exige, antes que un cambio de métodos, de contenidos, de organización, etc. de acuerdo con el discurso y con la mecánica escolar de la eficiencia pedagógica -lo que Vicente (2009, p. 120) ha denominado la ilusión didáctica-, una profunda 
transformación disciplinar que parta del cuestionamiento históricocrítico de los significados y de las consecuencias que tiene la disciplinarización o asignaturización de los aprendizajes del cuerpo:

- la desvinculación del aprendizaje con las necesidades de aprender y su incardinación en la obligación burocrática de aprobarsuperar etapas más o menos estandarizadas y abstractas de eficiencia física;

- la moralización de los aprendizajes en tanto que el vínculo con la superación o no del examen (por laxo que sea el baremo) supone una valoración ética del trabajo realizado para aprobar -o de las capacidades innatas, o de la obediencia a la autoridad pedagógicaque desvirtúa los intereses tanto del profesor como de los alumnos;

- la homogeneización y jerarquización de los procesos de enseñanza así como la sanción normalizadora de los sujetos sobre la base de un conocimiento genérico y universal de "el niño", "el alumno", "el cuerpo", etc. cuyos códigos epistemológicos impiden, como señala Varela (1995, p. 67), avanzar en la búsqueda de nuevos modelos de transmisión donde lo importante no sea la reproducción de lo ya sabido;

- la negación de la autonomía del sujeto para pensar su cuerpo y actuar con y sobre él (o no actuar) desde la propia experiencia y, sobre todo, desde las propias representaciones.

Dicho cuestionamiento histórico-crítico ha de evidenciar las contradicciones que el discurso técnico de la educación física soporta para contener su sentido dentro de los esquemas positivistas y tecnocráticos según los cuales, la educación física proclama desarrollar la libertad pero obtiene su reconocimiento tras un reclutamiento forzoso; afirma desarrollar valores democráticos pero se configura mediante una estructura jerárquica y bajo principios incontestables de autoridad; pretende desarrollar la autonomía pero no concede a penas ninguna responsabilidad decisoria a los alumnos sobre qué y cómo hacer con sus cuerpos; manifiesta desarrollar el sentido crítico pero fomenta la aceptación incondicional de la norma 
social dominante en cuanto a prácticas y representaciones del cuerpo; asegura promover el respeto a la diversidad pero trata la diferencia como carencia, retraso, inadaptación o torpeza; declara el valor de la pluralidad pero estructura de manera monolítica el desarrollo de competencias mediante programas sistemáticos y estandarizados.

Muy a menudo la crítica legitimista de la educación física contribuye a consolidar el modelo tradicional bajo la consideración de que, de todos modos, las actividades habituales de la educación física pueden seguir siendo válidas bajo la idea de que las prácticas que la conforman están inscritas en la sociedad y, por eso, facilitan la socialización; sin embargo, privilegia la integración mediante el éxito académico medido a través de logros personales. En todo caso, esta postura desatiende del carácter construido del currículum pero, sobre todo, se desentiende del sentido político que tiene la tradición selectiva resultante haciendo homogéneo lo que es heterogéneo y disolviendo el carácter ideológico de las prácticas en conceptos como "socialización", "desarrollo", "competencia", "actividad física".

\section{BREVES REFLEXIONES CONCLUSIVAS}

A este respecto, como señala Vicente (2001, p. 6) es preciso contemplar como cambio discutible, pero posible, incluso la quiebra del sistema mediante un profundo ejercicio genealógico que permita reconocer el carácter arbitrario de los saberes y de las prácticas que dominan el campo de la educación física, los cuales, amparados en la razón técnica, pueden ser eventualmente opresivos.

Desde luego, este proceso puede ser específico de la educación física de acuerdo con sus propias problemáticas; el propio Vicente (2007) plantea una alternativa de transformación disciplinar de la educación física escolar: "la educación física a demanda" en la que lo fundamental es la desescolarización de los aprendizajes del cuerpo en el sentido de desestructuración o, si se quiere, de-construcción de las estructuras académicas, incluida la obligatoriedad que las estructuras académicas dominantes imponen como condición de 
aprendizaje válido. Una propuesta que, no obstante, somete al debate público, entendiendo que ningún cambio que no proceda de dicho debate está abocado a reproducir los modelos imperantes.

En cualquier caso, nos parece que toda propuesta de transformación, en el sentido que plantea la Pedagogía Crítica, ha de trascender la inmediatez del discurso técnico especialmente cuando este, planteado desde la racionalidad instrumental, centra sus preocupaciones en la inmediatez de enseñar más y mejor. La emergencia de una Educación Física Crítica es tributaria de mayores pretensiones: es ineludible que la educación física se configure como una institución capaz de promover la concienciación de los sujetos implicados en la acción pedagógica en relación a los usos del cuerpo los propios y los de los demás; debe suscitar el cuestionamiento de los modos dominantes en la producción del conocimiento del cuerpo; debe ser capaz de producir códigos simbólicos e interpretaciones alternativos a los hegemónicos tal que posibiliten la impugnación de los modelos establecidos por la industria de los consumos del cuerpo; debe permitir aprender técnicas y desarrollar habilidades significativas, utilitarias y funcionales más allá del estrecho universo lúdico que a menudo sirve de coartada didáctica a los modelos corporales de las clases acomodadas; debe elaborar estrategias emancipatorias entendidas, no como desarrollo de capacidades del sujeto para bastarse a sí mismo en la lucha por el éxito social -de acuerdo con una concepción darwinista de la sociedad y su elementos-, sino como actitudes de reconocimiento de lo otro y de los otros que induzcan a la búsqueda de una sociedad más justa y más libre de acuerdo con ideales de emancipación. Todo ello implica compromiso ético y político, incluso un posicionamiento ideológico, que hasta ahora la escuela y la educación física no sólo no han propiciado sino que, por lo general, lo han considerado ajeno a la labor pedagógica e, incluso, como un elemento espurio cuando dicho compromiso no aparecía asociado a los valores meritocráticos.

Una propuesta de Educación Física Crítica ha de asumir como cometido prioritario la revisibilización de los sujetos -cuyos cuerpos siempre expresan la identidad social- porque revisibilizándolos estará 
colocando sobre la mesa del debate pedagógico la cuestión fundamental de la significación existencial, más allá del ludismo complaciente y más allá, también, de la competitiva y economicista servidumbre a los valores (réditos) de la industria cultural del cuerpo la cual, como ha señalado Vaz (2004, 33-34) parafraseando a Adorno, perpetúan la reificación de la corporalidad.

Emprender una transformación de la educación física desde la perspectiva de la pedagogía crítica exige trascender, en todo caso, de la consideración de la educación física como un particular momento escolar en el que la experiencia es un mero proceso de construcción de la motricidad a la consideración de la educación física como un espacio político en el que la experiencia es un nudo de tensiones culturales; un nudo de tensiones sobre el que inciden y confluyen distintas operaciones disciplinarias. Dicho de otro modo, habría que trascender de la consideración (la creencia) del cuerpo como un espacio neutro, vacío y disponible sobre el que se articulan cualidades, habilidades y técnicas según una relación de enseñanzaaprendizaje aséptica, a la consideración (el reconocimiento) del cuerpo como un espacio de permanente producción ideológica sobre el que se articulan redes de saber y de poder según una relación que es, antes que nada, política.

Por supuesto, como señalan Vicente (2001) o Muros (2006), entre otros, la formulación de la Educación Física Crítica sólo puede desarrollarse a través del debate abierto y comprometido y, más aún, a través de un proyecto colectivo en el que quepan todas aquellas propuestas que pugnan por una educación física más justa o que, simplemente, se plantean superar las contradicciones y las arbitrariedades de esta disciplina escolar. 
Critical of the physical education and Critical Physical Education in Spain. Status (critic) of the question

Abstract: This paper is aimed to make a distinction between a generic criticism of school physical education and the so called Critical Physical Education. After a review of the last decade scientific literature and a comparison of the conclusions emerging from it with the principles of Critical Pedagogy, this study will demonstrate that in Spain there does not exist any Critical Pedagogy but only very few well-intentioned approaches without solid support. In conclusion, this study will show the fundamental requirements to take into account for outlining both a theoretical and practical alternative in the framework of Critical Physical Education.

Keywords: Critical Physical Education. School. Ideology. Social change

Crítica da educação física e Educação Física Crítica na Espanha. Estado (crítico) da questão. Resumo: Este trabalho pretende distinguir entre críticas genéricas da Educação Física escolar e as formulações da Educação Física Crítica. Após a análise da produção teórica da última década e a comparação das suas propostas com os postulados da Pedagogia Crítica é inferido que na Espanha não há nenhuma representação desta corrente, mas apenas algumas aproximações e destacamentos voluntaristas sem um testemunho consistente. Finalmente, colocam-se os requisitos fundamentais e que a crítica da educação física deve levar em conta para a criação de uma alternativa teórico-prática da Educação Física Crítica. Palavras-chave: Educação Física Crítica. Escola. Ideologia. Mudança social 


\section{REFERENCIAS}

ADORNO, Theodor W. Dialéctica negativa. Madrid: Akal, 2011.

APPLE, Michael W. Ideología y currículo. Madrid: Akal, 1986.

APPLE, Michael W. La política del saber oficial: ¿Tiene sentido un currículum nacional? In: Volver a pensar la educación. Madrid: Morata, 1999. v.1, p. 153-171.

BOLTANSKI, Luc. Los usos sociales del cuerpo. Buenos Aires: Periferia, 1972.

BOURDIEU, Pierre. Notas provisionales sobre la percepción social del cuerpo. In: MILLS, C. WRIGHT et al. Materiales de sociología crítica. Madrid: La piqueta, 1986. p. 183-194.

DEVIS, José. El currículum de la educación física escolar y la Reforma educativa. In: HERNÁNDEZ, José et al. Educación Física escolar y deporte de alto rendimiento. Las Palmas de Gran Canaria, ACCAFIDE, 1998. p. 47-66.

ELIAS, Norbert. La sociedad de los individuos. Barcelona: Península, 1990.

FERNANDEZ VAZ, Alexander. Corporalidade e formaçao na obra de Theodor W. Adorno: questôes para a reflexâo crítica e prátic as corporais. Perspectiva, Florianópolis, v.22, n. esp. p. 21-48. 2004.

FERNÁNDEZ-BALBOA, Juan Miguel. La Educación Física desde una perspectiva crítica: de la pedagogía venenosa y el currículum oculto hacia la dignidad. In: LÓPEZ et al. Los últimos diez años de la Educación Física Escolar. Valladolid: Universidad de Valladolid, 2004. p. 215-225.

FERNÁNDEZ-BALBOA, Juan Miguel. Pedagogía crítica y educación física. Conceptos, Granada, n.6, p. 15-32, 1999.

FRAILE, Antonio. La didáctica de la educación física desde una visión crítica. Revista electrónica Interuniversitaria de formación del profesorado, Cáceres, v.2, n.1, 1999. Disponible en: <http://www.aufop.com/aufop/ uploaded_files/articulos/1224339991.pdf> Acceso en: 19 jul. 2012.

GIROUX, Henry. Las políticas de educación y de cultura. In: GIROUX, Henry; McLAREN, Peter. Sociedad, cultura y educación. Madrid: Miño y Dávila, 1998.

GÓMEZ, Isabel; PRAT, María. Hacia una Educación Física crítica y transformadora de las prácticas sociales: de la práctica a la reflexión y viceversa. Cultura y educación, Madrid, v.21, n.1, p. 9-17, 2009.

HORKHEIMER, Max; ADORNO, Theodor W. Dialéctica de la llustración. Madrid: Trotta, 2009. 
LEMOS, Lovane Maria et al. As contradições do processo de elaboração das diretrizes curriculares nacionais dos cursos de formação em Educação Física e os movimentos de resistência à submissão ao mercado. Movimento, Porto Alegre, v.18, n.3, p. 27-49, jul/set de 2012.

LÓPEZ, Víctor Manuel et al. Algunas reflexiones sobre educación física y Pedagogía Crítica. Retos, Almería, n.2, p. 30-35, 2002b.

LÓPEZ, Victor Manuel et al. Posibilidades, propuestas y experiencias para avanzar hacia una Educación física Crítica. Cuadernos Pastopas, Valladolid, n.1, p. 4-17, 2002a.

LÓPEZ, Víctor Manuel; GEA, J.M. Innovación, discurso y racionalidad en educación física. Revisión y prospectiva. Revista Internacional de medicina y ciencias de la actividad física y el deporte, Madrid, v.10, n.38, p. 245-270, 2010.

LÓPEZ, Víctor Manuel; MONJAS, Roberto; PÉREZ, Darío. Buscando alternativas a la forma de entender y practicar la educación física escolar. Barcelona: Inde, 2003.

MARIN, Elizara Carolina et al. Formação Continuada em Educação Física: Relação entre Mundo do Trabalho, Políticas Educacionais e Educação. Movimento, Porto Alegre, v.17, n.2, p. 259-278, abr/jun de 2011.

McLAREN, Peter. Pedagogía Crítica y cultura depredadora. Barcelona: Paidós, 1997.

MUÑOZ, Beatriz. La puesta en práctica de la Pedagogía Crítica: estrategias metodológicas críticas. Tándem, Zaragoza, n.20, p. 33-44. 2006.

PASCUAL, Carmina. La pedagogía crítica, una cuestión de ética. In: CONTRERAS, Onofre (coord.). La formación inicial y permanente del profesorado de Educación Física, Cuenca: Universidad de Castilla-La Mancha, 2000. p. 73-93.

PASCUAL, Carmina. Pedagogía crítica en la formación del profesorado de Educación Física, Revista Interuniversitaria de Formación del Profesorado, Zaragoza, n. 43 , p. 123-135, 2002.

SICILIA, Álvaro; FERNÁNDEZ-BALBOA, Juan-Miguel. La otra cara de la educación física desde una perspectiva crítica. Barcelona: Inde, 2005.

UREÑA, N. La otra cara de la educación física desde una perspectiva crítica (recensión). Cultura, Ciencia, Deporte, Murcia, v.3, n.1, p. 174-176, 2005.

VARELA, Julia. El estatuto del saber pedagógico. En: Volver a pensar la educación. Madrid: Morata, 1999. v. 2, p. 61-69.

VICENTE, Miguel. Creencias pedagógicas, desubjetivación del cuerpo y dominación cultural en la educación física escolar. Revista Brasileira de Ciências do Esporte, Campinas, v.31, n.1, p. 109-129, set. 2009. 
VICENTE, Miguel. El cuerpo sin escuela: proyecto de supresión de la educación física escolar y qué hacer con su detritus. Ágora para la educación física y el deporte, Valladolid, n.4-5, p. 57-90, 2007.

VICENTE, Miguel. Escuela y educación física en el contexto de la enseñanza por competencias. Reflexiones genealógicas desde la pedagogía crítica. Cultura, Ciencia, Deporte, Murcia, n.18, p. 161-170, 2011.

VICENTE, Miguel. La mirada del otro: escuela, cuerpo y poder. Revista de Educación Física, Renovar la Teoría y la Práctica, La Coruña, n.84, p. 5-14, 2001.

WILLIAMS, Raymond. Cultura y sociedad. Buenos Aires: Nueva Visión. 2001.

Endereço para correspondência:

Miguel Vicente Pedraz

Facultad de Ciencias de la Actividad Física y del Deporte

Universidad de León

Campus de Vegazana, s/n

24071 - León (España)

Recebido em: 15-11-2012

Aprobado em: 06-12-2012

Vovimento, Porto Alegre, v. 19, n. 01, p. 309-329, jan/mar de 2013. 